\title{
Sociopragmatic Failure: Struggling with Cross-Cultural Differences in Communication
}

\author{
Diana Stukan \\ University of Guanajuato, Division of Social Sciences and Humanities ${ }^{1}$
}

Received 13 July 2018 • Revised 1 August 2018 • Accepted 5 August 2018

\begin{abstract}
Communicative norms differ from one culture to another. Therefore, if language learners lack knowledge of appropriate linguistic behaviour in different countries, they may often experience some difficulties speaking a foreign language. In this case, sociopragmatic failure occurs. In the relevant literature, there is a tendency to explain sociopragmatic failure comparing various languages to English. However, the present article analyses the examples of this phenomenon in Ukrainian as compared to Mexican Spanish using the cooperative principle, the politeness principle and a concept of face as a guideline. The data used in this paper is retrieved from the author's personal experiences of intercultural interactions. The article suggests that sociopragmatic failure can often lead to a breakdown in communication. Thus, language teachers should provide pragmatic instruction to their learners.
\end{abstract}

Keywords: sociopragmatic failure, cooperative principle, politeness principle, face.

\section{Introduction}

In different societies and different communities, people speak differently; these differences in ways of speaking are profound and systematic, they reflect different cultural values, or at least different hierarchies of values; different ways of speaking, different communicative styles, can be explained and made sense of in terms of independently established different cultural values and cultural priorities (Wierzbicka, 1991: 69).

People in different societies or cultures speak differently because understanding of appropriate linguistic behaviour varies from one place to another. The purpose of this paper is to explore different cultural values related to language use, particularly I will examine the examples of sociopragmatic failure in Ukrainian and Mexican Spanish. I will first provide some theoretical information about the concept. I will then analyse the examples of sociopragmatic failure in the mentioned languages. Lastly, I will offer some implications for this concept in the area of language teaching.

My motivation for choosing this particular topic stems from my personal experiences of sociopragmatic failure. I am from Ukraine and my mother tongue is Ukrainian. I also learnt several foreign languages and I felt quite confident speaking them. However, I have never received

\footnotetext{
${ }^{1}$ The author is MA student at the University of Guanajuato, Division of Social Sciences and Humanities.
}

(C) Authors. Terms and conditions of Creative Commons Attribution 4.0 International (CC BY 4.0) apply. Correspondence: Diana Stukan, University of Guanajuato, Lascurain de Retana \#5, Guanajuato, MEXICO, 3600o. E-mail: dianastukan1@gmail.com. 
any pragmatic instruction from my language teachers that could help me behave linguistically correctly in those languages. Therefore, when I went abroad, I experienced many cross-cultural differences related to language use which impeded successful communication. Thus, through showing my personal experiences of sociopragmatic failure, I aim to suggest the importance of helping students to acquire pragmatic competence in language classrooms. Having expressed the aim of this paper and my interest in this topic, I will now explain what a sociopragmatic failure is.

- The norms of appropriate linguistic behaviour differ from one culture to another.

- If language learners are not aware of cultural norms placed on language use, they may experience a sociopragmatic failure speaking a foreign language with native speakers.

- Sociopragmatic failure can often lead to a breakdown in intercultural communication.

- In order for language learners to avoid sociopragmatic failure, it is important that they receive pragmatic instruction in their language classes.

\section{Sociopragmatic failure: Theoretical background}

Before I discuss a sociopragmatic failure per se, it is important to define the area of pragmatics. The term pragmatics refers to language in use (Dash, 2004; Thomas, 1983). To be more precise, it is the meaning that our utterances receive in a particular context. Dash (2004) argues that the discrepancy between what we mean and what we actually say is at the heart of pragmatics. Let us look at this example, it is customary to say to a newborn in Ukraine "How ugly" or "How bad". It does not mean that we intend to communicate that a baby looks ugly. We actually say it in order not to jinx a baby and to protect it from evil. Thus, if in any other situation one hears "how ugly" or "how bad", that will be offensive. However, in this particular context with a newborn, this utterance has a good intention.

I assume that if one foreigner comes to Ukraine and hears this phrase, he/she is likely to be surprised (or angry if it refers to his/her baby) and to misinterpret it. That will be a pragmatic failure. It can occur "on any occasion in which $\mathrm{H}$ [the hearer] perceives the force of S's [the speaker's] utterance as other than S intended he/she should perceive it" (Jaworski, 1994, p. 42). It may happen due to different cultural knowledge that we have about the world or due to the way we utter it linguistically. It was Thomas (1983) who distinguished two types of pragmatic failure:

(1) Pragmalinguisic failure. It occurs when a pragmatic force placed on an utterance by $\mathrm{S}$ differs from a force that is usually assigned to it by native speakers, or when "speech act strategies are inappropriately transferred from L1 to L2" (Thomas, 1983: 99).

(2) Sociopragmatic failure. It is defined as "social conditions placed on language in use" (Thomas, 1983: 99).

Pragmalinguistic failure is considered easier to overcome because it is a linguistic problem and can be corrected as a simple grammatical error. However, sociopragmatic failure is not as easy to correct as a pragmalinguistic one because it "stems from cross-culturally different perceptions of what constitutes appropriate linguistic behaviour" (Thomas, 1983, p.99). Thus, overcoming it means changing one's beliefs and values system (Jaworski, 1994). The example mentioned above would refer to sociopragmatic failure. It is grammatically correct but it may be misinterpereted by non-Ukrainian speakers due to their cultural perceptions of appropriate linguistic behaviour.

According to Thomas (1983), sociapragmatic failure can be caused by cross-cultural differences in the assessment of the following:

(1) The size of imposition. This refers to the notion about free and non-free goods.

Free goods are those that anyone could ask without any elaborate politeness 
strategies. Thomas (1983) provides an illustration of the Soviet Union, where cigarettes were almost free and anyone could ask for them without being extremely polite. This example can apply to Ukraine as a post-soviet country, too. I still remember when I was a child and men would come to my grandfather for some cigarettes because they knew he was a big smoker. I wonder if that would be the case in Western Europe where cigarettes were quite expensive. If one Russian or Ukrainian asks a random European person on the street for one cigarette, it will be a sociopragmatic failure as it is not appropriate there.

(2) Power and social distance. It refers to different styles of communication between people of different power and social status: for example, employers and employees, senior and young people, teachers and students, etc.

(3) Making references to what is considered taboo topics in L2 but can be freely discussed in L1. Taboos are topics that are inappropriate for discussions and they can vary from one country to another. The most common ones are sexual, racial, religious, etc. issues. For example, it is not common to ask about a salary in Ukraine.

(4) Cross-culturally different pragmatic ground rules. Pragmatic rules do not operate in the same way in different languages and the same utterance can be interpreted differently in different cultures. To illustrate, Jaworski (2008) describes the case of Polish and American English. It is common for Americans to say Let's do lunch as a polite farewell formula. However, Polish interlocutors perceive it as an invitation and are offended when Americans do not really come for a lunch. I must admit that similar situations happen with me in Mexico as well. I often hear from Mexicans We need to have a lunch/party one day or we must get together. I take it seriously and understand it as an invitation. However, it never happens, which disappoints me.

We have seen some examples from the literature which make it clear that sociopragmatic failures can not only affect linguistic production but also lead to a communication breakdown. This is because we interpret utterances, according to our cultural norms and understanding of the world. That is why something that sounds appropriate for speakers of one language may be rude or impolite for speakers of other languages, and vice versa. The concept of sociopragmatic failure is tightly connected with the notion of face-threatening act, briefly discussed in the next sub-section.

\subsection{Sociopragmatic failure and the concept of face}

According to Brown and Levinson's (1978) politeness theory, everyone has a face, which is his/her "emotionally invested" image (as cited in Vilkki, 2006: 324). A person has positive and negative face. Positive face is one's desire that his/her wants be appreciated in social interaction. Negative face is one's desire for "freedom of action and freedom from imposition" (Vilkki, 2006: 324). If one's positive or negative face is threatened, a face-threatening activity occurs. The theory assumes that most speech acts, such as requests, offers, compliments, etc. are face-threatening.

Cook (1989) asserts that the nature of face varies from society to society. These differences often cause misunderstanding between people from different cultures and/or speakers of different languages. Similarly, Beebe and Takahashi (1989) suggest that face-threatening acts are a source of many cross-cultural failures. It is due to different social norms of speaking in different languages and lack of pragmatic knowledge of how to perform face-threatening acts. Aiming at redressing face-threatening acts, different politeness strategies are involved. The main politeness principles are discussed in the next sub-section. 


\subsection{Pragmatic principles: Cooperation and politeness}

Spencer-Oatey and Jiang (2003) argue that people's communication is influenced by pragmatic principles. One of them is cooperative principle proposed by Paul Grice in 1975. The main point of this principle is that it is "known and applied by all human beings" (Cook, 1989: 29). It does not mean that people explicitly formulate them and apply in communication but rather that they speak as if they knew these rules. According to the cooperative principle, human beings obey four maxims in communication (Cook, 1989: 29): (1) be true (the maxim of quality), (2) be brief (the maxim of quantity), (3) be relevant (the maxim of relevance), and (4) be clear (the maxim of manner).

Cook (1989) notes that it is not necessary to obey all four maxims at once. For example, quality and quantity maxims do not always coincide because it is quite difficult to be brief and true at the same time. Furthermore, sometimes meanings derive from deliberate violations of the cooperative principle. For example, if I say "I have tones of exams to grade", my intention is not to lie but to explain to my interlocutor that I have much work to do; and the interlocutor understands it as such without blaming me as being untruthful.

Communication can be also explained by looking at Leech's (1983) politeness principle. Its main points can be conveyed as follows (Cook, 1989: 33): (1) do not impose, (2) give options, and (3) make your receiver feel good.

Cook (1989) admits that the politeness principle and the cooperative principle usually conflict with each other. This is because politeness and truth as well as politeness and brevity are often mutually incompatible. To provide a personal example, I live in Mexico, which is thousands kilometres away from Ukraine and from my parents. If they ask me how I am, I do not describe them in details all the difficulties that I may have. I would rather use a "white lie" because I know they cannot solve all my problems in Mexico being far away; they will only be preoccupied. I prefer violating the cooperative principle and make my parents feel calm.

The politeness principle is accompanied by six politeness maxims (Leech, 1983: 132):

(1) Tact maxim: minimize cost to other; maximize benefit to other.

The tact maxim is applied when $\mathrm{S}$ politely convinces $\mathrm{H}$ to do something that is beneficial to S. For example: one may use affirmative "Someone is knocking the door" instead of imperative "Open the door!". The first example is just a more polite way of asking the second one.

(2) Generosity maxim: minimize benefit to self; maximize cost to self.

This maxim can be explained in the following examples:

- You can lend me your bicycle (impolite); I can lend you my bicycle (polite).

- We must come to you for lunch (impolite); you must come to us for lunch (polite).

The offer and invitation are recognized as polite because they imply benefit to $\mathrm{H}$ (to get a bicycle; to be invited for a lunch) and cost to $\mathrm{S}$ (to lend a bicycle; to make a lunch).

(3) Approbation maxim: minimize dispraise of other; maximize praise of other.

The approbation maxim states: "Avoid saying unpleasant things about others, and more particularly, about H” (Leech, 1983: 135). We prefer to praise others or, if we cannot do so, to remain silent. To illustrate, "You are an excellent cook" is an appropriate and polite utterance as compared to "You are an awful cook". The second represents violation of the approbation maxim and should be avoided.

(4) Modesty maxim: minimize praise of self; maximize dispraise of self. 
This maxim is the other side of the approbation maxim. Breaking the modesty maxim equals boasting, which is usually considered impolite. Compare: A: You were so kind. B: Yes, I was, wasn't I. It is not common to response to praise as in B.

(5) Agreement maxim: minimize disagreement between self and other; maximize agreement between self and other.

Disagreement is considered impolite; it is a dispreferred second because it is less common (Cook, 1989). Thus, we always try to mitigate it. For example, compare: A: This book is very interesting, isn't it? B: Oh no, it is so boring vs. A: This book is very interesting, isn't it? B: Yes, it is. But there are some boring parts. Disagreement in the first example is impolite. In the second example, $\mathrm{H}$ mitigates it by performing partial disagreement.

Leech (1983) describes a situation, in which an English speaker compliments a garden of a Japanese woman. However, the woman keeps on denying a compliment that denotes violation of the agreement maxim as well as shows that the modesty maxim is more powerful in Japanese societies.

(6) Sympathy maxim: minimize antipathy between self and other; maximize sympathy between self and other.

This maxim is applied in speech acts, such as congratulation, commiseration and expressing condolences. To illustrate, instead of saying "I am terribly sorry to hear that your dad died", it is more preferable and typical for human conversation to say "I am terribly sorry to hear about your dad". Both examples sound correct. However, referring to the propositional context of the death in the first sentence might carry a note of impoliteness because it is unfavourable to $\mathrm{H}$.

Using the cooperative principle and the politeness principle as well as general knowledge about the world in our communication, makes it possible for a person to interpret pragmatic meaning of an utterance (Cook, 1989). These two principles work differently in different countries. A failure to apply them in our language use, according to socio-cultural norms in a particular country, may lead to a sociopragmatic failure. I will illustrate personal examples of sociopragmatic failure in the following section.

\section{Examples of sociopragmatic failure}

As I have mentioned before, I am originally from Ukraine but currently I live in Mexico. Before coming to Mexico, I had visited some other countries. Thus, I experienced several sociopragmatic failures, especially in Mexico because the cultures are fairly different. In crosscultural communication, people usually rely on the knowledge of social norms and politeness principles that operate in their L1. In my case, I also make use of my previous cultural experiences, which sometimes helps and sometimes makes the matters even worse. I this section, I will discuss a few sociopragmatic failures that I faced in my cross-cultural interactions.

(1) Failure to perceive Spanish Qué tal / Cómo estás? or English 'How are you?' as a greeting

Jaworski (1994) discussed in his article that Polish learners of English perceive a greeting 'How are you?' as an actual question for information. So they answer how they really feel, be it awful, sick or happy. In this aspect Ukrainian is similar to Polish. We ask 'How are you?' only when we really want to know it and interlocutors usually respond honestly how they feel. Nevertheless, the question 'How are you?' in English and Qué tal / Cómo estás? in Spanish are used as phatic functions [macro-function of language focused on opening the channel of communication (Cook, 1989)]. My previous experience with English helped me to avoid sociopragmatic failure in Spanish. However, it is still difficult for me to perceive it as a greeting. I sometimes do not even answer because I know that an interlocutor is not interested in how I 
actually feel. My avoidance of response might be perceived as a face-threatening act. This example also shows that the politeness principle is more powerful in Mexico while the cooperative principle is in Ukraine. Ukrainians value being true more than applying elaborate politeness strategies in communication.

\section{(2) Misinterpretation of Mexican "ahorita"}

Mexican ahorita, which could be literally translated into English as "right now", is the most mysterious word in Mexican Spanish for me. It is not clear if it means now, in a minute, in an hour or never. I first heard ahorita in one language school where I used to work as an English teacher. It was a response to my request to receive some materials. I assumed that my interlocutor was going to fulfil the request immediately. Instead she just looked at me puzzled and I figured out that she did not intend to give me the required materials at that particular moment. This sociopragmatic failure illustrates that the concept of time is treated differently in both cultures. Ukraine could be regarded as a monochronic culture as compared to polychronic Mexico. Monochronic cultures are the ones that view time as linear, keep schedules and accurate planning while polychronic cultures treat time as a philosophical concept and are engaged in several activities at a time (Prykarpatska, 2008).

\section{(3) Avoidance of refusal by Mexican Spanish speakers}

This example is related to the previous one. Refusal like many other speech acts is a face-threatening act because it is a dispreferred response to an offer or invitation. Mexican Spanish speakers prefer to be polite and to mitigate it. Instead of saying 'no', they may just answer ahorita, más tarde [later] or use any other strategies to avoid refusal. Ukrainian as well as English speakers would rather perform a face-threatening act and refuse, violating the agreement maxim. Mexicans prefer to ignore the quality maxim but to be polite.

\section{(4) Different way to express phatic function in Mexican and Ukrainian culture}

Another sociopragmatic failure usually occurs to me in Mexico when I see acquaintances passing by. In Ukraine, I would greet them with 'Hi', even though I know that we will not have a conversation. However, it appeared that it is appropriate linguistic behaviour in Mexico to say Adios [bye] if you know that your conversation will not go further than greeting each other. In Ukraine, it would mean that you do not wish to see that person and that would definitely be a sociopragmatic failure.

\section{(5) Failure to be brief}

Mexican culture is quite expressive and people tend to describe some situations emotionally and in many details. One time my student came to me after a class and started to tell me a long history about an adventure that occurred to him and his family the day before. I was confused and irritated, and could not understand why he was telling me this story. So I asked him to go directly to the point. At the end I figured out that it was an explanation of his reason for being absent in a previous class. Instead of going directly to the point, the student provided too many details before actual explanation. In Ukraine, it would be inappropriate linguistic behaviour in an academic context. Here we can observe violation of quantity maxim, whose main point is to be brief. My irritation can be seen as threat to my student's positive face because his want of being excused for the absence has not been appreciated.

(6) Different understanding and linguistic expression of power and social distance in Mexican and Ukrainian culture

In Ukraine, the distinction between formal and informal 'you' is taken quite seriously. Young people always use formal 'you' with senior people as well as students with teachers and teachers with students or when you meet someone for the first time, etc. It is a way of being polite and failure to do it is absolutely inappropriate. However, the distinction between two forms of 
addressing is not so strictly followed in Mexico. It would not be a socipragmatic failure if you address someone tú [informal 'you'] in an official institution or in any other public place. Besides, social norms related to teacher-student relationship in both countries are rather different. Students are more familiar and uninhibited with teachers in Mexico but in Ukraine the social distance between both sides is larger. To illustrate, it is highly rude to address a teacher in Ukraine with informal 'you' while in Mexico it would be quite appropriate.

Second example for this category refers to performing requests in Ukrainian and Spanish. In Ukraine, it is not customary to use 'please' in informal requests to close people. If one says 'can/could you please...?' to close friends or family members, he/she diverges and sets a large social distance. We use this formula mostly in formal contexts. We may say 'please' in imperative requests rather than in interrogative ones with familiar people. Nonetheless, in Mexico it is considered quite impolite or even rude if you do not use the formula 'can/could you please...?' or especially if you perform an imperative request. This means that the tact maxim is valued differently in both cultures. Two examples, described here, show that Ukraine values social distance more than Mexico.

\section{(7) Different taboo topics}

In the previous section, I stated that taboo topics can vary from one country to another. One taboo topic in Ukraine which can be freely discussed in Mexico is health problems, especially the ones related to stomach. Once, one of my students told me that he missed a class because he had diarrhoea. It would be absolutely inappropriate and quite embarrassing in Ukraine. I often face this sociopragmatic failure with my boyfriend, who is Mexican. When I feel sick, he usually asks me many personal questions, which I do not feel free to discuss with anyone. However, this behaviour offends him because he thinks that I do not trust him. In this situation, I threaten his positive face because his wish to help me is misunderstood. At the same time, he threatens my negative face because my desire for freedom from imposition is not respected.

In this section, I illustrated a few sociopragmatic failures that I experienced in my cross-cultural interactions. We could see that they impede our understanding and consequently can lead to a breakdown in communication. In order to reduce the possibility of occurrence of this phenomenon, we should learn social norms and politeness principles that operate in L2. It does not mean that we need to change our way of expressing different macro functions of language because there is no right or wrong way to do it. It depends on socio-cultural norms placed on language use that differ from one country to another. However, we do need to adjust our discourse when using L2 according to what is considered appropriate linguistic behaviour in that language. Concerning me, I figured out most of pragmatic principles in the foreign languages I know by myself, having experienced several failures. In order for learners to be more prepared for crosscultural communication, I propose some implications of the concept of sociopragmatic failure for the area of language teaching in the following section.

\section{Implications for the area of language teaching}

Dash (2004: 12) states that pragmatics is "indispensable part of language learning and which has received insufficient attention in acquisition”. The primary goal for learning a language is communication and ability to convey meaning which is central to the area of pragmatics. In spite of this, pragmatics is usually neglected in the language classrooms. Several authors agree upon the importance of teaching pragmatics to language learners (Dash, 2004; Eslami-Rasekh, EslamiRasekh, \& Fatahi, 2004; Fernandez, 2008; Jaworski, 1998; Thomas, 1983).

According to Thomas (1983), linguistic knowledge consists of grammatical competence and pragmatic competence. The former is the knowledge of phonology, syntax and semantics. The latter refers to "the ability to use language effectively in order to achieve a specific 
purpose and to understand language in context" (Thomas, 1983: 92). Nevertheless, the author argues that language teachers focus only on grammatical competence. Therefore, students lack pragmatic skills and cannot communicate fluently. Then a question arises: Why do we teach languages if at the end of the day learners are not able to interact? Thomas (1983) notes two reasons for leaving pragmatics aside in language teaching:

(1) Pragmatic description has not received the exactness level of grammar, describing linguistic competence.

(2) It is a delicate area and it is not completely clear how to teach it.

It is worth mentioning that Thomas wrote this in 1983; however, little has changed since that time. Language teaching does not seem to be progressing in terms of pragmatic instruction. To provide an example, I work in the institution which claims to follow communicative language teaching. Nonetheless, there is no place for teaching pragmatics in its language syllabus. Then it appears that it cannot be really called communicative language teaching because successful communication is at the heart of pragmatics. I agree that it is rather difficult to teach pragmatics and to explain the importance of it to the students because there is lack of materials dedicated to developing pragmatic competence. Most of the textbooks focus only on grammatical competence. Thus, teaching pragmatics demands much effort from language teachers, but trying something new is the only way to improve.

Eslami-Rasekh et al. (2004) show in their study that pragmatic instruction works. Their research was conducted with 66 Iranian advanced learners of English and focused on three speech acts: request, apology and complaint. The participants were divided into two groups: a control group receiving normal instruction and an experimental group that additionally received pragmatic instruction. About 30 minutes of each two hour class were dedicated to pragmatically oriented tasks, such as descriptions, explanations, teacher-fronted discussions, cooperative grouping and role-plays. At the beginning of the study, a multiple choice pragmatic awareness test with 26 situations was administered to the participants. At the end of the course, a similar questionnaire was given to the learners in order to compare the results. The findings showed that pragmatic instruction facilitates students' pragmatic development and contributes to their speech act comprehension processes.

So, how to help language learners to acquire pragmatic competence? Researchers give some recommendations. Dash (2004) proposes applying role-plays and dramas in classes with proper description of different contexts. He even suggests adding pragmatic instruction in teaching L1 in order for learners to understand that people of varying cultural backgrounds can understand certain utterances differently. Jaworski (1994) mentions three ideas of teaching pragmatics in language classes:

(1) Demonstrating the role of phatic communion and linguistic routines;

(2) Pointing out specific nature of formulaic expressions;

(3) Discussing the potential problems of miscommunication as a result of transfer of pragmatic knowledge from L1 to L2.

An interesting exercise is described by Bardovi-Harlig (1992). The author recommends bringing to a class different L2 speech acts and asking students to record similar speeches in their L1 in order to analyse possible pragmatic similarities and differences in L1 and L2. This type of activity would be more relevant to the students' context and raise their pragmatic awareness.

Thus, it is highly significant for course designers to find some spare space in language syllabi for pragmatics classes. Moreover, I think pragmatics must be taught starting from beginning levels so that students understand the importance of knowing cross-cultural differences 
in communication. Also, I would argue that pragmatic instruction should be given not only to language learners but also in teacher-training programmes in order for future teachers to have necessary tools for raising pragmatic awareness among their students.

\section{Conclusions}

This essay explored sociopragmatic failure, analysing some examples in Ukrainian vs. Mexican Spanish, and several other concepts related to it, such as face-threatening act and the pragmatic principles. To summarize, we generally tend to avoid face-threatening acts, applying different cooperation and politeness maxims in our communication. These politeness maxims have different power in various cultures. If we apply them incorrectly in a particular language/culture, a sociopragmatic failure occurs.

I examined seven examples of performing different speech acts in Ukrainian and Mexican Spanish. The discussion allows me to conclude that the cooperative principle is more valued in Ukraine while the politeness principle is more powerful in Mexico. Ukrainian speakers, on the one hand, generally tend to be true even if it means performing a face-threatening act. Mexican speakers, on the other hand, prefer to mitigate face-threatening acts by applying elaborate politeness strategies. All the examples explained in this paper were faced by me and they often led to breakdowns in my cross-cultural communication. In order to avoid this, I believe language learners need to receive pragmatic instruction in language classes and learn how to be polite in a foreign language. We do not need to become different persons learning a second language. But we should know cultural norms that operate in this language in order to be able to fully express ourselves and not to get into embarrassing situations.

\section{Acknowledgements}

I should thank the University of Guanajuato for giving me an opportunity to study my Master's there and to work on interesting projects. I would also like to express my gratitude to my teachers Troy Crawford and Pierre-Luc Paquet for their useful pieces of advice and valuable feedback on this paper.

This research did receive any specific grant from funding agencies in the public, commercial, or not-for-profit sectors.

\section{References}

Bardovu-Harlig, L. (1992). Pragmatics as part of teacher education. TESOL Journal, 1(1), 28-32.

Beebe, L. M., \& Takahashi, T. (1989). Sociolinguistic variation in face-threatening speech acts: Chastisement and disagreement. In M. R. Eisenstein (Ed.), The dynamic interlanguage: Empirical studies in second language variation (pp. 199-216). New York, NY: Springer Science + Business Media.

Cook, G. (1989). Discourse. New York, NY: Oxford University Press.

Dash, P. (2004). Cross-cultural pragmatic failure: A definitional analysis with implications for classroom teaching. Asian EFL Journal, 6(3), 1-17.

Eslami-Rasekh, Z., Eslami-Rasekh, A., \& Fatahi, A. (2004). The effect of explicit metapragmatic instruction on the speech act awareness of advanced EFL students. TESL-EJ, 8(2), 1-11. 
Fernandez, A. L. (2008). Teaching culture: Is it possible to avoid pragmatic failure? Revista Alicantina de Estudios Ingleses, 21, 11-24.

Jaworski, A. (1994). Pragmatic failure in a second language: Greeting responses in English by Polish students. IRAL-International Review of Applied Linguistics in Language Teaching, 32(1), 4156.

Leech, G. (1983). Principles of pragmatics. New York, NY: Longman.

Prykarpatska, I (2008). Why are you late? Cross-cultural pragmatic study of complaints in American English and Ukrainian. Revista Alicantina de Estudios Ingleses, 21, 87-102.

Spencer-Oatey, H., \& Jiang, W. (2003). Explaining cross-cultural pragmatic findings: Moving from politeness maxims to sociopragmatic interactional principles. Journal of Pragmatics, 35, 1633-1650. DOI: 10.1016/So378-2166(03)00025-0

Thomas, J. (1983). Cross-cultural pragmatic failure. Applied Linguistics, 4(2), 91-112.

Vilkki, L. (2006). Politeness, face and facework: Current issues. Linguistic Association of Finland Journal of Linguistics, 322-332.

Wierzbicka, A. (1991). Cross-cultural pragmatics: The semantics of human interaction. Berlin: Mouton de Gruyter. 